\title{
Sensory exotropia due to keratoconus and review of the literature
}

This article was published in the following Dove Press journal:

Clinical Ophthalmology

15 October 2013

Number of times this article has been viewed

Suleyman Ciftci ${ }^{1}$

Ali Simsek ${ }^{2}$

Eyup Dogan'

Leyla Ciftci ${ }^{3}$

'Department of Ophthalmology, Diyarbakır Training and Research Hospital, Diyarbakır; ${ }^{2}$ Department of Ophthalmology, Faculty of Medicine, Adıyaman University, Adıyaman; ${ }^{3}$ Department of Cardiology, Faculty of Medicine, Dicle University, Diyarbakır, Turkey
Correspondence: Suleyman Ciftci Diyarbakır Eğitim ve Araștırma Hastanesi Göz Hastalıkları Polikliniği, 21000 Diyarbakır, Turkey

Tel +90 4l 22570206

$\mathrm{Fax}+9004122245267$

Email ciftci1977@hotmail.com
Abstract: This case report describes a 17-year-old boy with sensory strabismus due to keratoconus and an ipsilateral nodular lesion of the bulbar conjunctiva. The aligned eye was the right eye and keratoconus in this eye was of late onset. Vision in the left eye was poor and keratoconus was advanced in this eye. Due to the longstanding nature of the keratoconus and its occurrence in a developmentally sensitive period, sensory exotropia had developed in the left eye. There was a nodular lesion of the bulbar conjunctiva in the ipsilateral eye. If keratoconus occurs before the age of 7 years and the prolonged visual loss is not corrected, sensory strabismus can develop, as in this patient.

Keywords: keratoconus, sensory exotropia, childhood

\section{Introduction}

Keratoconus is the most common primary ectasia. It classically occurs in the second decade of life, has its onset during puberty, and affects both sex and all ethnicities. The estimated prevalence in the general population is 54 per 100,000. Using a combination of four indices, ie, central K (descriptive of central steepening), the I-S value (inferiorsuperior dioptic asymmetry), Sim K, and the SRAX index (skewed radial axes), Rabinowitz was able to distinguish $98 \%$ of keratoconus videokeratographs from a group of normal controls, ${ }^{1}$ and in marked keratoconus, simple observation of the presence of keratometry over 47.20 D can make the diagnosis. ${ }^{2}$ Sensory strabismus occurs due to temporary or permanent loss of vision in one or both eyes. The prevalence of sensory strabismus is $5 \%-9 \%$. When it occurs in adults, exotropia tends to be considered. ${ }^{3}$

\section{Case presentation}

We present the case of a 17-year-old boy with bilateral keratoconus, exotropia, and a nodular lesion of the bulbar conjunctiva in the left eye. A prism cover test revealed a 45 prism D exodeviation (Figure 1). The aligned eye was the right eye and the keratoconus in this eye was of late onset. Vision in the left eye was poor and the keratoconus was advanced in this eye. The patient has a corrected visual acuity of 6/9 in his better and aligned eye and an acuity of $1 / 60$ in the affected eye. Keratometric measures were $42.75 \mathrm{D}$ at an axis of $28^{\circ}$ and $49.0 \mathrm{D}$ at an axis of $118^{\circ}$ in the right eye, and $52.0 \mathrm{D}$ at an axis of $154^{\circ}$ and 58.75 $\mathrm{D}$ at an axis of $64^{\circ}$ in the left eye. SimK1 was $45.24 \mathrm{D}$ at an axis of $113^{\circ}$ and $\operatorname{Sim} \mathrm{K} 2$ was $42.75 \mathrm{D}$ at an axis of $25^{\circ}$ in the right eye. Sim K of the left eye could not be obtained because of a high steep keratometry value. Refraction in the right eye was $+1.5,-7.5 \times 25^{\circ}$ and refraction in the left eye could not be obtained (Figure 2). 


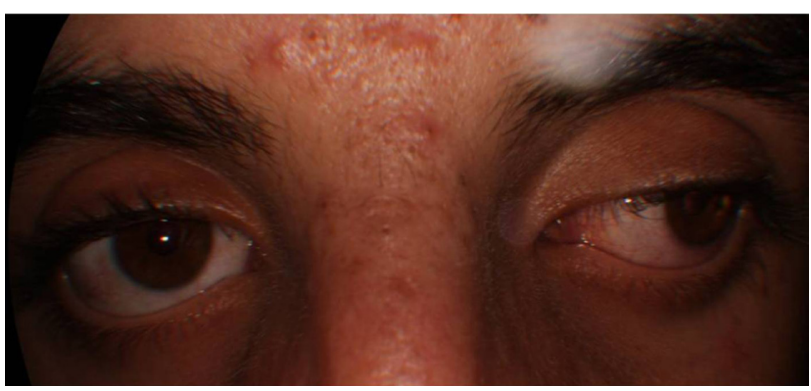

Figure I Clinical photograph of the patient showing exotropia in the left eye.

\section{Discussion}

A search of PubMed yielded only two studies reporting development of sensory strabismus after keratoconus. In these reports, binocular function in patients with longstanding asymmetric keratoconus was investigated by the authors.
The first of these reports was by Sherafat et al, who investigated a database of approximately 350 patients with keratoconus. ${ }^{4}$ Only 20 of these patients were identified as having abnormal binocular function. ${ }^{4}$ The abnormalities described in their study were central suppression of the deviating eye, reduction or loss of stereopsis with a microtropia when wearing a scleral lens, and a manifest exotropia with suppression when the poorer eye was uncorrected. The earliest age at which keratoconus was diagnosed in their series was 12 years. Sherafat et al accepted the age of diagnosis as being the age of onset of keratoconus, and suggested that the adult visual system in these cases had been affected by prolonged visual deprivation. However, it has generally been assumed that the sensitive period ends at about 7 years of age and that the adult human visual system is not affected by visual deprivation. ${ }^{5-9}$ It is possible that the age of onset
A

NAME

08_AUG_2011 PM 04:42

NO:3481

VD: 13.75

CYL: MIX

$<$ R> S C A

$16+1.50-7.5025$

$\mathrm{PD}=59 \mathrm{~mm}$

KRT. DATA

$\begin{array}{cc}<\mathrm{R}> & \mathrm{D} \\ \mathrm{H} & 42.75\end{array}$

V 49.00

MM

7.90

6.87

AVE $\quad 46.00$

7.39

CY

$-6.25$

$<\mathrm{L}>*$
$\mathrm{~V}$

D

52.00

58.75

AVE 55.25

CYL
B
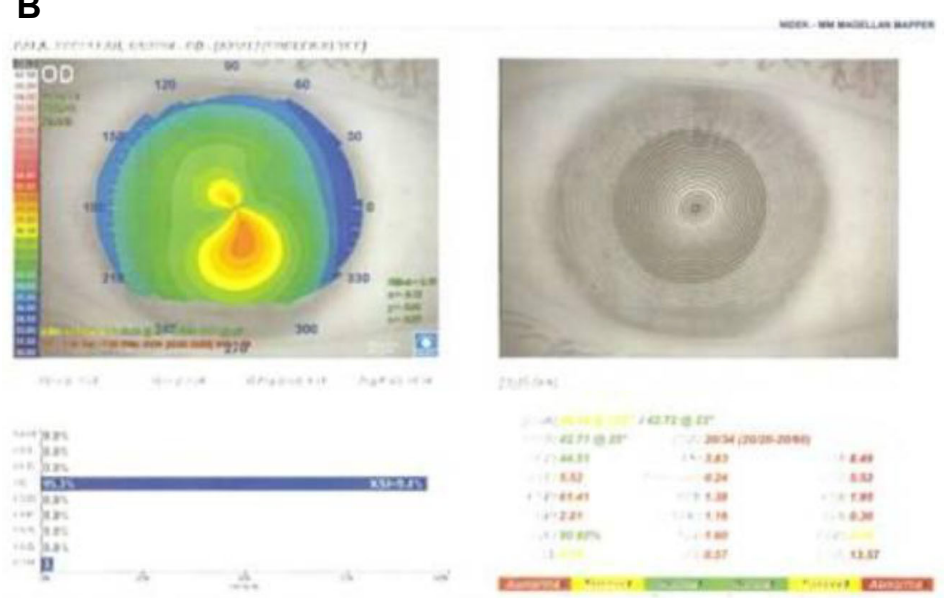

28

118

28
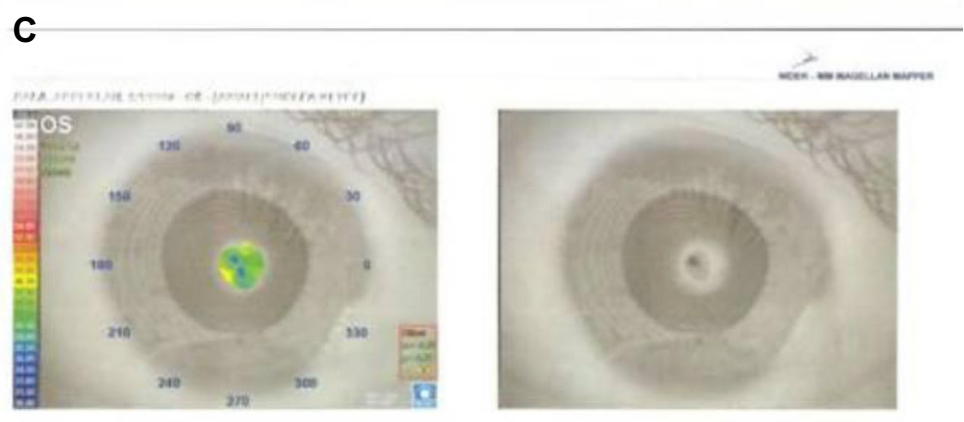

154

$\begin{array}{cc}\text { MM } & \text { A } \\ 6.50 & 154 \\ 5.75 & 64 \\ 6.13 & \\ -6.75 & 154\end{array}$

TOPCON 
in the patients reported on by Sherafat et al may have been earlier than puberty and therefore their visual deprivation may have settled.

The second report was by Khan and Al-Shamsi, who investigated a database of 103 patients with keratoconus and identified abnormal binocular function due to longstanding keratoconus in only seven patients. ${ }^{10}$ In their series, six patients had persistent exotropia. After intervention to improve visual acuity, six patients complained of constant binocular diplopia that resolved after successful surgical alignment. The authors explained that resolution of diplopia by realignment of the eyes enabled suppression of scotoma and freedom from diplopia. The major limitation of their study was the lack of information provided on age at onset of keratoconus and a lack of explanation regarding the etiology of suppression of keratoconus.

In our study, neither the patient nor his parents knew when the keratoconus had started, but did give two clues, ie, a history of childhood-onset strabismus and vernal conjunctivitis with eye rubbing. There was a nodular lesion of the bulbar conjunctiva in the ipsilateral eye. This lesion had invaded the cornea, was surrounded by injected blood vessels, and looked like pseudoepitheliomatous hyperplasia or a sequel of keratoconjunctivitis in childhood (Figure 3). Pseudoepitheliomatous hyperplasia is an inflammatory lesion that usually occurs on the eyelid, but rarely in the bulbar conjunctiva. However, there was no active inflammation of the conjunctiva in our patient, so this lesion may have been a sequel of keratoconjunctivitis in childhood.

The causes of poor eyesight are varied, with chorioretinal atrophy, congenital cataract, optic atrophy, retinal disease, complicated cataract, leucoma, coloboma, high myopia, congenital glaucoma, penetrating trauma, contusional eye

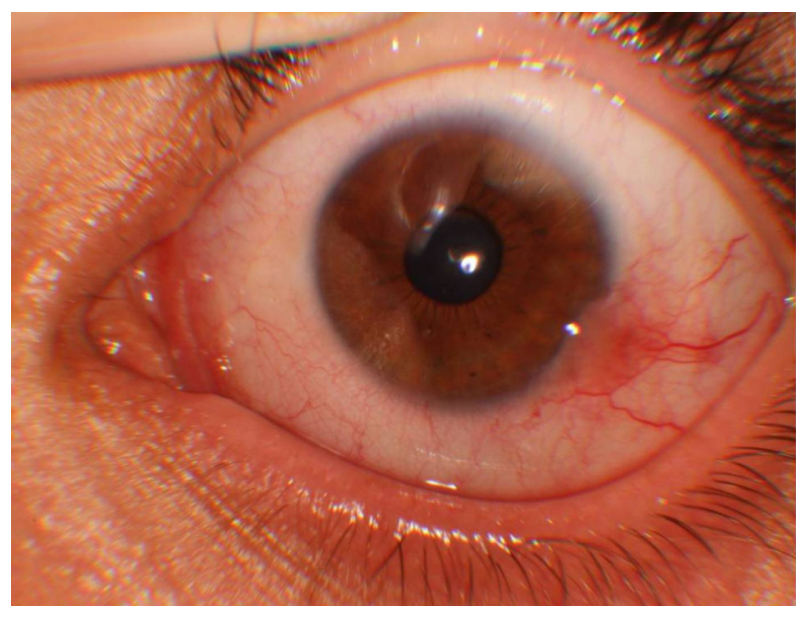

Figure 3 Clinical photograph of a nodular lesion in the bulbar conjunctiva. trauma, and traumatic cataract being the more common causes. ${ }^{11}$ Sensory strabismus also appears to have various causes, but is not a consequence of keratoconus, ${ }^{1,12}$ which typically commences at puberty and commonly affects both eyes. However, when one eye is more severely affected than the other, visual loss can be prevented by glasses or contact lenses. The visual loss is gradual and occurs primarily as a result of irregular astigmatism and myopia. ${ }^{13}$ The sensitive period for development of suppression ends when the keratoconus has settled.

The presence of a nodular lesion of the bulbar conjunctiva and a history of vernal conjunctivitis and eye rubbing in this patient confirms vernal keratoconjunctivitis in childhood. Rabinowitz ${ }^{1}$ and Sugar ${ }^{12}$ consider that atopic conjunctivitis and eye rubbing are a cause of keratoconus. The probable scenario in this patient is that vernal keratoconjunctivitis caused the childhood keratoconus, which became advanced in the left eye, and the prolonged visual loss was not corrected before the age of 7 years. This prolonged visual loss resulted in sensory strabismus. We believe that the abnormal binocular function due to keratoconus in our patient and in the cases reported by other authors occurred before the age of 7 years.

\section{Conclusion}

Here we report a patient with approximately 45 prism D of constant sensory exotropia. The etiology of strabismus due to keratoconus is not well defined in the literature. Review of the relevant literature suggests that keratoconus seldom begins in the sensitive period during which abnormal visual experience affects visual development and may induce sensory exotropia. In our patient, sensory exotropia had developed because of prolonged visual loss based on the keratoconus in his poorer eye.

If keratoconus occurs before the age of 7 years and prolonged visual loss is not corrected, sensory strabismus can develop, as in our patient.

\section{Acknowledgment}

Patient consent was obtained for use of Figures 1 and 3 accompanying this paper.

\section{Disclosure}

The authors report no conflicts of interest in this work.

\section{References}

1. Rabinowitz YS. Keratoconus. SurvOphthalmol. 1998;42(4):297-319.

2. Sugar J. Stromal corneal dystrophies and ectasias. In: Yanoff M, Duker JS, Augsburger JJ, editors. Ophthalmology. 2nd ed. St Louis, MO: Mosby; 2003. 
3. Merino P, Mateos C, Gómez De Liaño P, Franco G, Nieva I, Barreto A. [Horizontal sensory strabismus: characteristics and treatment results]. Arch SocEspOftalmol. 2011;86(11):358-362. Spanish.

4. Sherafat H, White JE, Pullum KW, Adams GG, Sloper JJ. Anomalies of binocular function in patients with longstanding asymmetric keratoconus. Br J Ophthalmol. 2001;85(9):1057-1060.

5. Boothe RG, Dobson V, Teller DY. Postnatal development of vision in human and non-human primates. Annu Rev Neurosci. 1985;8: 485-545.

6. Von Noorden GK. Amblyopia: a multidisciplinary approach. Invest Ophthalmol Vis Sci. 1985;26:1704-1716.

7. Wiesel TN. Postnatal development of the visual cortex and the influence of environment. Nature. 1982;299:583-591.

8. Sloper JJ. Competition and co-operation in visual development. Eye. 1993;7:319-331.
9. Vaegan, Taylor D. Critical period for deprivation amblyopia in children. Trans OphthalmolSoc U K. 1979;99:432-439.

10. Khan AO, Al-Shamsi H. Binocular diplopia following vision restoration in patients with keratoconus and sensory strabismus. Strabismus. 2008;16(1):19-22.

11. Oliveira BF, Bigolin S, Souza MB, Polati M. [Sensorial strabismus: a study of 191 cases]. Arq Bras Oftalmol. 2006;69(1):71-74. Portuguese.

12. Sugar J, Macsai MS. What causes keratoconus? Cornea. 2012;31(6): 716-719.

13. Jhanji V, Sharma N, Vajpayee RB. Management of keratoconus: current scenario. Br J Ophthalmol. 2011;95(8):1044-1050.
Clinical Ophthalmology

\section{Publish your work in this journal}

Clinical Ophthalmology is an international, peer-reviewed journal covering all subspecialties within ophthalmology. Key topics include: Optometry; Visual science; Pharmacology and drug therapy in eye diseases; Basic Sciences; Primary and Secondary eye care; Patient Safety and Quality of Care Improvements. This journal is indexed on Submit your manuscript here: http://www.dovepress.com/clinical-ophthalmology-journal

\section{Dovepress}

PubMed Central and CAS, and is the official journal of The Society of Clinical Ophthalmology (SCO). The manuscript management system is completely online and includes a very quick and fair peer-review system, which is all easy to use. Visit http://www.dovepress.com/ testimonials.php to read real quotes from published authors. 